\title{
SOSIALISASI TATA CARA PENGGUNAAN OBAT YANG BENAR PADA MASYARAKAT DESA SENGGIGI PROVINSI NUSA TENGGARA BARAT
}

\section{SOCIALIZATION OF PROCEDURES FOR USING MEDICINES IN SENGGIGI VILLAGE OF WEST NUSA TENGGARA PROVINCE}

\author{
Candra Eka Puspitasari $\left.{ }^{*}\right)$, Nisa Isneni Hanifa, NMAR Dewi, Luthfanto Hafizhuddin, Dani Syaiful
}

Akbar

\author{
Program Studi Farmasi, Fakultas Kedokteran, Universitas Mataram
}

Jalan Majapahit Nomor 62, Kota Mataram, Provinsi NTB, 83115

${ }^{*}$ Alamat korespondensi : candrapuspitasari@unram.ac.id

(Tanggal Submission: 8 November 2019, Tanggal Accepted: 16 April 2020)

\begin{abstract}
ABSTRAK
Penggunaan obat memerlukan perhatian khusus, sebab ketidaksesuaian penggunaannya seperti tidak tepat dosis dan cara pemakaian akan menimbulkan permasalahan yang dapat mengancam jiwa. Kegiatan pengabdian ini dilakukan dengan cara sosialisasi terkait beberapa topik antara lain cara memperoleh dan penggunaan obat yang benar, baik golongan obat bebas, bebas terbatas, maupun keras. Kemudian dilakukan penilaian terkait penggunaan obat yang benar yang bertujuan untuk mengukur sejauh mana pemahaman masyarakat tentang penggunaan obat di Desa Senggigi Nusa Tenggara Barat dengan adanya sosialisasi. Metode yang digunakan adalah deskriptif menggunakan alat ukur kuesioner Gema Cermat (Gerakan Masyarakat Cerdas menggunakan Obat) dan Dagusibu (Dapat, Gunakan, Simpan, Buang). Responden yang terlibat berjumlah 13 orang yang merupakan kader dengan rentang usia antara 20 hingga 58 tahun. Hasil pengisian kuesioner Gema Cermat menunjukkan bahwa pemahaman masyarakat berada dibawah nilai minimal dengan rata-rata skor sebesar $48,46 \pm 16,25$. Selanjutnya, penilaian menggunakan kuesioner Dagusibu menunjukkan bahwa seluruh responden memperoleh antibiotik di layanan kesehatan resmi yaitu apotek $(30,77 \%)$ dan puskesmas $(69,23 \%)$. Namun pemahaman mengenai manfaat dan cara menggunakan antibiotik masih rendah, seperti $84,61 \%$ menyatakan dapat memperoleh amoksisilin tanpa resep dokter. Tingkat pemahaman responden yang relatif masih rendah menunjukkan bahwa perlu intervensi lanjutan untuk meningkatkan pemahaman penggunaan obat kepada masyarakat setempat.
\end{abstract}

Kata Kunci : pengetahuan, penggunaan, obat, antibiotik, masyarakat

\section{PENDAHULUAN}

Obat merupakan zat yang digunakan untuk mencegah dan menyembuhkan penyakit serta pemulihan dan peningkatan kesehatan bagi penggunanya yang memiliki dua sisi yaitu kemanfaatan dan efek samping (BPOM, 2015). Perlu adanya kehati-hatian dan pemahaman pada penggunaan obat terlebih jika digunakan secara mandiri (swamedikasi)(Anderson,1979). Swamedikasi dapat menjadi sumber permasalahan penggunaan obat atau dikenal dengan Drug
Related Problems (Mil, Horvat, \& Westerlund, 2017). Antibiotika merupakan obat yang bekerja dengan cara membunuh atau menahan pertumbuhan bakteri yang digunakan berdasarkan jenis bakteri yang menginfeksi tubuh dan harus digunakan secara rasional untuk menghindari kejadian resistensi/kekebalan. Resistensi adalah kemampuan bakteri untuk tidak terpengaruh terhadap agen-agen antibakteri atau antibiotika (WHO, 2015).

Desa Senggigi terletak di kabupaten Lombok Barat, provinsi Nusa Tenggara Barat 
dengan luas wilayah 1.703 Ha yang terdiri dari 4 Dusun yaitu Dusun Senggigi, Dusun Kerandangan, Dusun Loco, dan Dusun Mangsit. Total penduduk di desa Senggigi berjumlah \pm 4.653 jiwa dimana terdapat 1643 KK yang bermata pencaharian disektor pariwisata, pertanian, peternakan, perkebunan, dan nelayan. Sebagian besar masyarakat Senggigi adalah pengangguran (tidak/belum bekerja), wiraswasta, dan pengurus rumah tangga. Tingginya angka pengangguran di desa Sengggigi disebabkan akibat rendahnya kesadaran masyarakat untuk mendapatkan pendidikan (Kantor Desa Sengigigi, 2016). Pengobatan secara mandiri atau swamedikasi, tingkat Kognisi dan IQ (Inteligence Quotation) menjadi faktor penyebab permasalahan dalam penggunaan obat (Kaufmann, Stämpfli, Hersberger, \& Lampert, 2015). Menambahkan, pengetahuan dan tingkat pendidikan terbukti memiliki pengaruh terhadap perilaku KADARZI (Keluarga Sadar Gizi) (Rahardjo-Setiyowati, 2011). Oleh sebab itu, berdasarkan data sebaran penduduk di desa Senggigi dan pentingnya pemahaman penggunaan obat yang benar maka perlu adanya penilaian mengenai pemahaman menggunakan obat secara benar.

\section{METODE KEGIATAN}

Program pengabdian masyarakat ini dilakukan dengan sosialisasi yang dilanjut dengan praktek langsung dengan metode Cara Belajar Insan Aktif (CBIA). Tujuannya untuk menilai pengetahuan masyarakat terhadap cara penggunaan obat yang benar di Desa Senggigi, Nusa Tenggara Barat berdasarkan perbedaan jenis kelamin, usia dan tingkat pendidikan. Responden yang dipilih merupakan tim penggerak PKK di Desa Senggigi baik laki-laki maupun perempuan, perorangan dan bersifat sukarela. Tim ini bertugas melakukan pemberdayaan keluarga meliputi segala upaya bimbingan, pembinaan, dan pemberdayaan agar keluarga dapat hidup sejahtera, maju dan mandiri. Pada proses pengambilan data diperoleh 17 responden, namun hanya 13 responden yang berkenan mengisi lembar evaluasi. Ketiga belas responden memiliki rentang usia antara 20 hingga 58 tahun.

Evaluasi terhadap sosialisasi ini dilakukan menggunakan dua jenis kuesioner yaitu kuesioner Gema Cermat dan Dagusibu. Kedua kuesioner telah digunakan secara luas oleh Dinas Kesehatan Provinsi Nusa Tenggara Barat melalui Apoteker Agent of Change (AoC) ditiap wilayah. Data yang diperoleh pada penelitian ini berupa data kualitatif yakni nominal (jenis kelamin dan jawaban kuesioner dagusibu), ordinal (tingkat pendidikan), serta data kuantitatif yakni rasio (usia responden dan jawaban kuesioner gema cermat). Selain analisis deskriptif, juga dilakukan penilaian hubungan antara jenis kelamin, usia dan tingkat pendidikan terhadap pemahaman penggunaan obat menggunakan uji Fisher Exact dengan bantuan IBM SPSS versi 24.

\section{HASIL DAN PEMBAHASAN}

Penggunaan obat secara mandiri atau dikenal dengan istilah swamedikasi dapat menjadi salah satu faktor permasalahan dalam penggunaan obat (Drug Related Problems) jika tidak diikuti dengan pemahaman yang baik. Permasalahan yang akan dihadapi pengguna obat antara lain reaksi samping seperti alergi dan interaksi obat (Mil, Horvat, \& Westerlund, 2017). Terdapat 37 faktor resiko permasalahan penggunaan obat antara lain penggunaan NSAIDs (anti nyeri), permasalahan kognitif dan tingkat IQ yang rendah, ketidak pahaman pasien dan rendahnya pengetahuan dalam menggunakan obat, pengobatan mandiri tanpa adanya resep dokter, dan permasalahan bahasa (Kaufmann et al., 2015).

Masyarakat desa Senggigi pada umunya merupakan pengangguran, pengurus rumah tangga dan berwirausaha sebab rendahnya pemahaman mengenai pentingnya pendidikan. Usaha yang digeluti pada umumnya dibidang pariwisata, pertanian, peternakan, perkebunan, dan nelayan. Hal ini sesuai dengan geografis Desa Senggigi yang berada di pesisir pantai sepanjang \pm 3 KM (Data Desa Senggigi, 2016). Responden pada penelitian ini didominasi oleh perempuan $(92,31 \%)$ dengan usia dewasa (17-45 tahun) $(84,60 \%)$ dan berpendidikan rata-rata SMA (46,15\%). Meskipun demikian masih ada $38,46 \%$ responden yang hanya menuntaskan bangku Sekolah Dasar (Tabel 1).

Tabel 1. Karakteristik Responden

\begin{tabular}{lccc}
\hline & $\begin{array}{c}\text { Jumlah } \\
\text { responden } \\
\text { (orang) }\end{array}$ & $\begin{array}{c}\text { Persen- } \\
\text { tase } \\
(\%)\end{array}$ & $\begin{array}{c}\text { Rata- } \\
\text { rata }\end{array}$ \\
\hline Jenis Kelamin & & & \\
\hline
\end{tabular}




\begin{tabular}{lccc}
\hline Laki-Laki & 1 & 7,69 & \\
Perempuan & 12 & 92,31 & \\
\hline Usia & & & $37,62 \pm$ \\
& & & 11,184 \\
$\quad$ Dewasa (20 - & 11 & 84,60 & \\
$\quad 45$ tahun) & & & \\
Lansia Awal & 2 & 16,40 & \\
$\quad$ (46-55 tahun) & & & \\
\hline Pendidikan & & & \\
Tamat SD & 5 & 38,46 & \\
Tamat SMP & 2 & 15,38 & \\
Tamat SMA & 6 & 46,15 & \\
\hline
\end{tabular}

Selain itu, berdasarkan pengamatan di lapangan, sebesar $46,15 \%$ responden merupakan ibu rumah tangga, 38,36\% responden enggan menyebutkan aktivitas hariannya, sedang sisanya sebagai pekerja honorer di lingkungan Kantor Desa Senggigi serta berwirausaha masing-masing sebesar $7,69 \%$. Hanya responden yang bekerja menjadi staf honorer yang menyebutkan penghasilan yang diperoleh yakni sebesar Rp1.350.000,-/bulan sedang sisanya menyatakan tidak memiliki penghasilan tetap.

Pada pengabdian dilakukan sosialisasi terkait Gema Cermat yakni Gerakan Masyarakat Cerdas menggunakan Obat yang merupakan program Kementerian Kesehatan RI. Materi yang diberikan meliputi penjelasan terkait Gema Cermat dan kegiatan turunannya. Materi dilanjutkan menggunakan pendekatan Dagusibu, yakni Dapat, Gunakan, Simpan, Buang. Pada materi ini, peserta akan diajak memahami dimana tempat yang aman untuk mendapatkan obat, bagaimana cara menggunakan obat dengan benar terutama ditekankan pada penggunaan antibiotik. Selain itu, peserta dijelaskan terkait bagaimana cara menyimpan obat agar zat aktif obat tidak mengalami kerusakan yang berujung efek terapi yang diharapkan tidak tercapai. Disela-sela materi, peserta diajak menyanyikan lagu 5 jari untuk memudahkan mengingat bagaimana cara mengkonsumsi obat dengan benar.Pada materi Buang, peserta dijelaskan bagaimana cara membuang obat yang benar yakni agar tidak terjadi penyalahgunaan sampah obat hingga tidak mencemari lingkungan. Materi yang ada disampaikan menggunakan slide powerpoint bergambar yang bertujuan memudahkan visualisasi peserta. Selain itu, peserta diinformasikan mengenai Alat Kesehatan (Alkes) dan Perbekalan Kesehatan Rumah Tangga (PKRT) yang sehari-hari digunakan. Hal ini bertujuan agar peserta dapat menggunakan alkes dan PKRT secara tepat guna dan aman setelah melakukan pengecekan nomor registrasi.

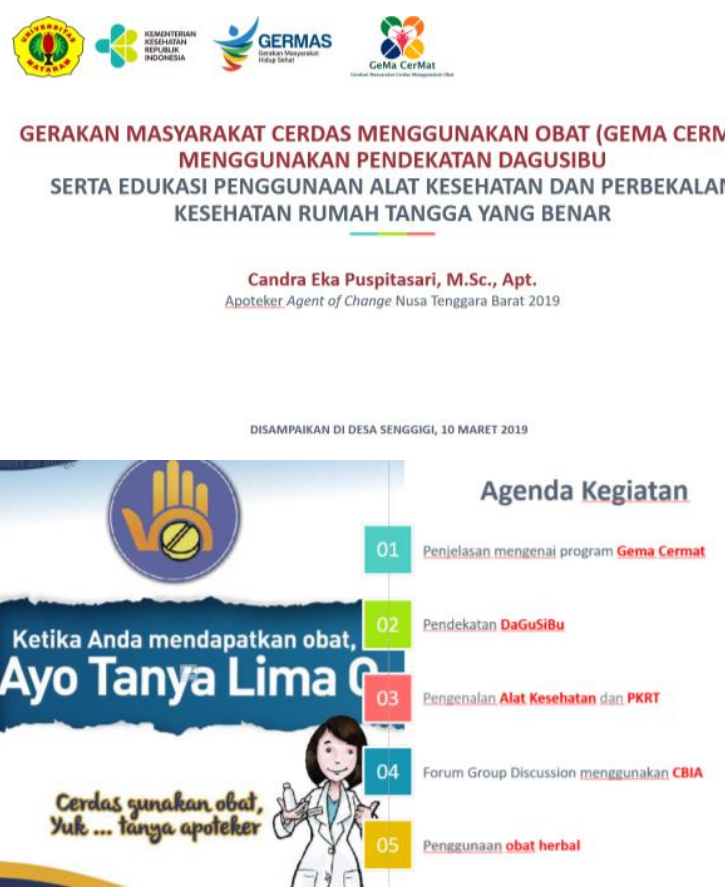

Gambar 1. Materi sosialisasi yang disampaikan

Sesi selanjutnya merupakan Forum Grup Discussion dengan menggunakan pendekatan Cara Belajar Insan Aktif (CBIA). Pada sesi ini, peserta dibagi menjadi beberapa kelompok dimana satu kelompok terdiri dari 3-4 orang. Setiap kelompok akan dipandu oleh 2 orang tutor dan mendapatkan satu paket obat-obatan yang sudah disiapkan dan lembar jawaban. Peserta diminta untuk menganalisis obat-obatan yang telah disiapkan kemudian mempresentasikannya. Metode ini diasumsikan seperti simulasi saat peserta sedang memilih obat di toko obat maupun apotek. Harapannya peserta akan semakin mudah memahami karena berinteraksi langsung dengan contoh obat-obatan, alkes, maupun PKRT yang sering digunakan. Kemudian sesi dilanjutkan dengan evaluasi pemahaman peserta menggunakan dua kuesioner yang berbeda, yakni kuesioner Gema Cermat dan Dagusibu. 


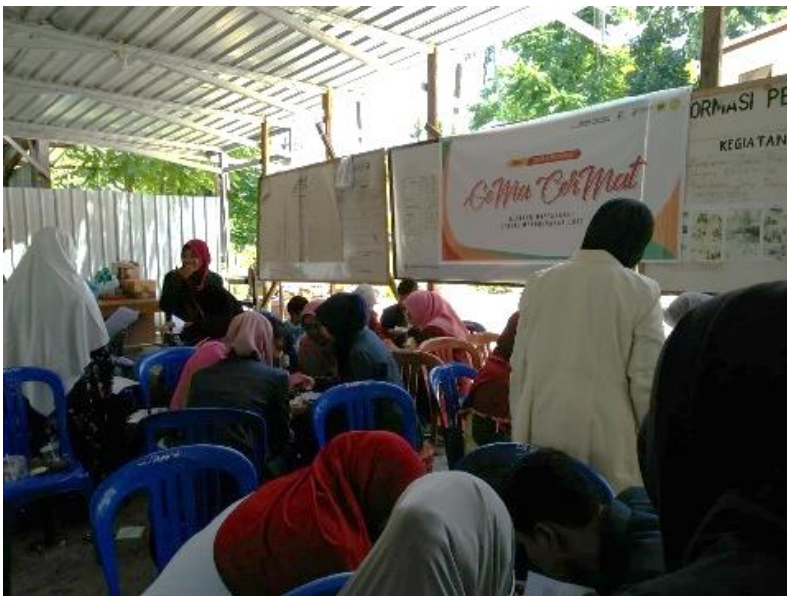

Gambar 2. Pengarahan kepada Masyarakat tentang pengisian kuesioner
Penilaian kuesioner Gema Cermat yang terdiri dari sepuluh pertanyaan memiliki rata-rata skor capaian akhir 48,46 $\pm 16,25$ dengan nilai responden bergerak dari 10 hingga 70 . Berdasarkan ketetapan Instalasi Farmasi Dinas Kesehatan Provinsi Nusa Tenggara Barat, responden dikatakan telah memenuhi standar minimal capaian pemahaman jika skor sekurangkurangnya adalah 50. Untuk dapat melihat adanya hubungan antara usia, jenis kelamin, dan pendidikan terhadap pengetahuan masyarakat terkait penggunaan obat dilakukan uji Fisher's Exact. Hasil uji menunjukkan bahwa tidak terdapat hubungan yang signifikan baik pada usia, jenis kelamin, maupun pendidikan terhadap pengetahuan penggunaan obat yang dinilai dengan melihat skor kuesioner Gema Cermat (Tabel 2).

Tabel 2. Pertanyaan Kuesioner Gema Cermat

\begin{tabular}{cl}
\hline $\begin{array}{c}\text { No } \\
\text { Pertanyaan }\end{array}$ & \multicolumn{1}{c}{ Pertanyaan } \\
\hline 1 & Gema Cermat merupakan singkatan dari \\
2 & Sasaran utama dari Gema Cermat \\
3 & 5 O merupakan 5 hal yang minimal harus diketahui sebelum menggunakan obat \\
4 & Obat paten yaitu \\
5 & Obat bebas terbatas adalah \\
6 & Cara minum obat yang benar jika tiga kali sehari \\
7 & Obat yang hanya dapat dibeli dengan resep dokter, pada kemasan diberi tanda \\
& lingkaran merah dengan gari tepi hitam dan huruf K ditengah yang menyentuh garis \\
& tepi dinamakan jenis obat apa? \\
9 & Cara penggunaan antibiotik yang benar dalah \\
10 & Cara menyimpan obat dalam bentuk sirup harus \\
\hline
\end{tabular}

Tabel 3. Hubungan Karakteristik Responden terhadap pengetahuan masyarakat menggunakan obat

\begin{tabular}{|c|c|c|}
\hline $\begin{array}{c}\text { Karakteristik } \\
\text { Responden }\end{array}$ & $\begin{array}{c}\text { Skor Akhir } \\
\text { Kuesioner } \\
\text { Gema } \\
\text { Cermat }\end{array}$ & Kesimpulan \\
\hline Usia & $0,304^{\mathrm{a}}$ & $\begin{array}{l}\mathrm{p}>0,05 \text { maka } \\
\text { tidak terdapat }\end{array}$ \\
\hline $\begin{array}{l}\text { Jenis } \\
\text { Kelamin }\end{array}$ & $0,385^{b}$ & $\begin{array}{c}\text { hubungan } \\
\text { antara variabel }\end{array}$ \\
\hline Pendidikan & $0,074^{b}$ & yang diuji \\
\hline
\end{tabular}

Penilaian kuesioner Dagusibu dilakukan secara deskriptif berdasarkan persentase jawaban dari pertanyaan yang diajukan. Kuesioner ini menggabungkan pengetahuan responden terkait dimana dapat memperoleh obat yang benar, bagaimana menggunakan obat secara tepat, bagaimana cara menyimpan obat dan bagaimana cara membuang obat sisa atau rusak dan kadaluarsa yang dimiliki.

Berdasarkan hasil pengisian kuesioner, seluruh responden menyatakan memperoleh antibiotik di fasilitas kesehatan yakni apotek $(30,77 \%)$ dan puskesmas $(69,23 \%)$. Dimana $84,62 \%$ menggunakan antibiotik atas rekomendasi dokter. Sebanyak 53,85\% responden menyimpan antibiotik di rumah 
mereka sebagai persediaan yang sebagian besar merupakan sisa dari penggunaan sebelumnya. 46,15\% menggunakannya untuk mengatasi radang. Antibiotik golongan Penicilin yang paling banyak digunakan adalah amoksisilin yakni sebesar 84,61\%. Sebanyak 76,92\% membeli semua antibiotik sesuai dengan yang dianjurkan dan sebanyak 53,85\% beralasan tidak memiliki cukup uang untuk memeriksakan diri ke dokter sehingga menggunakan antibiotik secara bebas.

\section{KESIMPULAN DAN SARAN}

Tingkat pemahaman responden di Desa Senggigi yang relatif rendah meski telah memperoleh sosialisasi menunjukkan bahwa perlu adanya intervensi lanjutan untuk meningkatkan pemahaman penggunaan obat kepada masyarakat setempat hingga membentuk pola insan cerdas dan bijak menggunakan obat.

\section{UCAPAN TERIMA KASIH}

Penulis mengucapkan terima kasih kepada Kader Kesehatan Desa Binaan Fakultas Kedokteran Universitas Mataram yaitu Desa Senggigi, Kelompok Pengabdian Masyarakat Himpunan Mahasiswa Farmasi Universitas Mataram yang telah membantu pelaksanaan kegiatan di lapangan, Apotek Citra Medika atas kerjasama obat dan alat kesehatan serta Dinas Kesehatan Provinsi Nusa Tenggara Barat berupa keterlibatan Apoteker Agent of Change dan alat bantu peraga.

\section{DAFTAR PUSTAKA}

Anderson, J.A.D,1979. "Historical Background to Self-care, Dalam Anderson J.A.D. (ed). SelfMedication. The Proceedings of Workshop on Self Care, London: MTP Press Limited Lancaster, 10-18.

BPOM, 2015, Modul GNPOPA (Gerakan Nasional Peduli Obat dan Pangan Aman) http://www.pom.go.id/files/2016/1pu_g npopa.pdf diakses tanggal 5 Juli 2019

Kaufmann, C. P., Stämpfli, D., Hersberger, K. E., \& Lampert, M. L. (2015). Determination of risk factors for drug-related problems: A multidisciplinary triangulation process. BMJ Open, 5(3), 1-7. https://doi.org/10.1136/bmjopen-2014006376

Mil, J. W. F. van, Horvat, N., \& Westerlund, T. (2017). Classification for Drug related problems (C) 2003-2017. 'The PCNE Classification ,' V 8.01, 1-10.

WHO. 2015. Antibmicrobial Resistance, https://www.who.int/en/newsroom/fact-sheets/detail/antimicrobialresistance diakses tanggal 5 juli 2019 